\title{
AUTOBIOGRAFIA E REPRESENTAÇÃO DE SI MESMO NA NARRATIVA E NA CRÔNICA DE ANTÓNIO LOBO ANTUNES
}

\author{
Paula Renata Lucas Collares* \\ Pontifícia Universidade Católica do Rio Grande do Sul
}

\begin{abstract}
Resumo: O presente artigo centra-se na leitura analítica de algumas crônicas publicadas no Primeiro Livro de Crónicas (1998) e do romance Sôbolos rios que vão (2010), de António Lobo Antunes. Este estudo aponta como o tempo, a memória, a infância e as suas respectivas manifestações, como os aspectos aparentemente autobiográficos, estão ligados à tessitura de algumas crônicas e do romance. Com efeito, é possível ver como a ficção configura possibilidades ficcionais e biográficas. Os elementos estruturais da narrativa do escritor português António Lobo Antunes tornam-se peças de um quebra-cabeça manipulado pelo autor. No Primeiro Livro de Crónicas e no romance, António Lobo Antunes revisita o passado, não à maneira "romântica", mas a partir de um processo crítico e de auto-reflexão. Sendo assim, tentaremos encontrar sentido nas marcas intertextuais, nos deslizamentos da voz do autor, no contato entre o discurso autobiográfico e o literário. A análise fundamenta-se na teoria da literatura, com apoio dos estudos de Philippe Lejeune.
\end{abstract}

Palavras-chave: António Lobo Antunes. Autobiografia. Ficção. Crônica.

\footnotetext{
"A casca são pessoas que eu conheço, como as casas, como as ruas, preciso de um cenário sólido que eu sinta como muito real. Depois visto-as por dentro e por fora conforme me apetece. Eu tenho de partir de uma base real (ANTUNES, 2008, p.151).
}

Em Sôbolos rios que vão, penúltimo livro publicado por António Lobo Antunes, o narrador Antoninho ou Senhor Antunes, deitado em uma cama de hospital, vítima de dores causadas pelo cancro no intestino, recupera os eventos do passado: a infância, o avô surdo, o

\footnotetext{
* Graduada em Licenciatura Letras - Português e Literaturas de Língua Portuguesa na Universidade Federal de Pelotas. Mestre em Letras, na área de História da Literatura pela FURG. Doutoranda em Teoria da Literatura pela PUCRS

${ }^{1}$ DIAS, Ana Sousa [1992]. "Um escritor reconciliado com vida". In: ARNAUT, Ana Paula (ed.). 1979-2007. Confissões do Trapeiro. Coimbra: Almedina, 2008. p.151-156.
} 
pai com a criada na despensa, etc. O livro está organizado em uma espécie de diário entre os dias 21 de março a 4 de abril de 2007. Na mesma época, António Lobo Antunes esteve hospitalizado devido a um cancro no intestino. Para jogar com o aparente autobiografismo, o autor opta por narrador em terceira pessoa. Também nas crônicas, António Lobo Antunes diversas vezes retratou a sua infância. Entretanto, nesses discursos, como nos diz Pedro Mateus em "A infância na cronística de António Lobo Antunes", a "infância aparece [...] como um tempo em que a existência ainda fazia sentido" (2004, p.157). Já que, na maioria das crônicas, estamos diante de uma infância idealizada em contraposição a um presente problemático. Deseja-se analisar como os eventos da infância são recuperados e como se realiza o entrecruzamento entre a ficção e a biografia nas crônicas e no romance Sôbolos rios que vão. Desta forma, analisaremos os diálogos entre o discurso narrativo e o discurso autobiográfico, percebendo, sobretudo, como a personagem rearticula o seu passado recuperado sempre através da memória.

Este trabalho não pretende teorizar a respeito da crônica como gênero, já que a intenção é analisar as crônicas de António Lobo Antunes a partir do tratamento do tempo e da memória quando o autor utiliza uma matriz autobiográfica (a infância em Benfica, o pai, a mãe, o avô, etc). Pretende-se estudar aquelas crônicas que estabelecem um diálogo muito estreito entre a ficção e a biografia.

Cada vez mais estamos diante de narrativas autoficcionais, autobiográficas e metaficcionais. Todas na intenção de dar um sentido diferente ao eu que se coloca nos textos, demandando sempre uma leitura vacilante que coloca em questionamento se tal identificação extratextual pode conferir ao texto um halo de verdade. Essa estratégia narrativa mostra que a relação entre a realidade e a ficção é bastante complexa, já que o biográfico e o fíctício se intercambiam. Sendo assim, a leitura requer que o leitor entre nos jogos criados pelo autor, entendendo que quem diz "eu" no texto é e não é o autor. A ênfase está no processo de contar histórias ao invés da história contada.

Phillipe Lejeune, ao principiar o estudo das narrativas autobiográficas, deparou-se com uma série de discussões, que são sempre suscitadas, a respeito da linha tênue entre os gêneros biográfico, autobiográfico e ficcional. Em Le pacte autobiographique, o teórico estabeleceu alguns limites desse gênero. Os discursos autobiográficos constituem um campo literário indeterminado e impreciso, em que o leitor é obrigado a fazer algum tipo de comprovação ou relação com a biografia do autor. Lejeune considera que em um discurso autobiográfico há uma relação entre o narrador, o personagem e o autor, possibilitada através 
do pacto autobiográfico plenamente estabelecido com o leitor. A afirmação do teórico já manifesta quão ambígua e sutil é a diferença entre os gêneros, isso acontece devido ao fato de que, na maioria dos discursos metaliterários, há também uma relação entre a identidade do narrador, do personagem e do autor. Diz-nos Lejeune que "o que define a autobiografia para quem a lê é, antes de tudo, um contrato de identidade que é selado pelo nome próprio" (LEJEUNE, 2008, p.33).

Vinte e cinco anos após a publicação de Le pacte autobiographiphe, Lejeune escreve um novo livro onde reformula a sua teoria e percebe que:

\begin{abstract}
o romance autobiográfico literário aproximou-se da autobiografia a ponto de tornar mais indecisa do que nunca a fronteira entre esses dois campos. Essa questão é estimulante: em que condições o nome próprio do autor pode ser percebido por um leitor como 'fictício' ou 'ambíguo'? Como se articulam, nesses textos, o uso referencial da linguagem, no qual as categorias de verdade (que se opõe à mentira) e a realidade (que se opõe à ficção) permanecem pertinentes, e a prática da escrita literária, na qual essas categorias se esvanecem? (LEJEUNE, 2008, p.59)
\end{abstract}

A ambiguidade encontra-se ainda no fato de que, para Lejeune, uma autobiografia é uma narrativa retrospectiva que uma pessoa faz da sua própria existência. Entretanto, essa não poderia ser a definição de um romance metaficcional? Lejeune conclui que "certamente é impossível atingir a verdade, em particular a verdade de uma vida humana" (LEJEUNE, 2008, p.104). Dessa forma, a história da autobiografia seria a história do seu modo de leitura. "Não se trata de buscar, aquém, uma inverificável semelhança com uma pessoa real, mas sim de ir além, para verificar, no texto crítico, o tipo de leitura que ele engendra, a crença que produz" (LEJEUNE, 2008, p.47).

As afirmações de Lejeune serão de extrema importância para analisarmos as evocações e remissões ao passado que ocorrem tanto na crônica quanto no romance. Segundo António Lobo Antunes, as crônicas ocupam um lugar menos importante em sua produção, mas, mesmo assim, o autor segue escrevendo e publicando os seus livros de crônicas ${ }^{2}$. As crônicas de Lobo Antunes apareceram na década de 90 no jornal Público e agora podem ser lidas na revista Visão. Em entrevista à María Luisa Blanco, Lobo Antunes afirma que a sua escrita cronística leva em consideração o fato de que "as pessoas querem uma coisa ligeira que não as faça pensar muito, que as divirta um pouco" (BLANCO, 2002, p.113) e, devido a esse "espírito das crónicas", elas não teriam nenhuma importância. Sendo assim, segundo o autor as suas crônicas "são coisinhas sem nenhuma pretensão. E tenho a impressão de que é um público diferente que lê essas coisinhas" (BLANCO, 2002, p.113).

${ }^{2}$ O Quarto Livro de Crónicas foi publicado em 2011. 
Dificilmente pode-se confiar fielmente nas palavras de um escritor, principalmente, quando ele está a falar sobre o seu processo de composição. E principalmente, no caso de António Lobo Antunes em que as crônicas obedecem a uma estratégia narrativa muito utilizada em seus romances. Desta forma, "as crônicas de domingo" não estão ali só para o mero entretenimento de um público menos especializado. E ao agrupá-las em um livro, segundo Carlos Reis, “elas são avaliadas como tendo méritos literários importantes, entre eles o de inaugurarem uma outra forma de pensar sobre o gênero" (ANTUNES apud BRAGA, 2007, p.17).

Neste trabalho, tenciona-se analisar aquelas crônicas que oscilam entre a ficcionalização e o testemunho pessoal através de um discurso em que, como nos diz Pedro Mateus em "A infância na cronística de António Lobo Antunes", a infância surge "como um tempo em que a existência ainda fazia sentido" (MATEUS, 2004, p.157). Na maioria das crônicas aparecem as "evocações de um passado dolorosamente perdido, imagens míticas de um tempo de ordem, de inocência e de paz, das «meninas de saias curtas e botas brancas», das «primas de bikini» [...] por oposição a um presente asfixiante, descolorido, monótono e entediante" (MATEUS, 2004, p.157). As crônicas escolhidas pertencem ao primeiro Livro de Crónicas, publicado em 1998. Tanto nas crônicas quanto no romance escolhido surge o entrecruzamento entre a ficção e a autobiografia. Pretende-se analisar os diálogos entre o discurso narrativo e o discurso autobiográfico, percebendo, sobretudo, como a personagem rearticula o seu passado através da linguagem.

Nas crônicas de caráter mais intimista, escritas em primeira pessoa e com recorrentes evocações ao passado, não importa pensar se o texto é biográfico ou literário, mas sim evidenciar o trabalho que é realizado com a linguagem como um jogo de espelhos, uma brincadeira de revela/esconde. É a partir da escrita que aparentemente um eu biográfico pode ser lido como um eu ficcionalizado. Na entrevista concedida à Blanco, Lobo Antunes diz, ao ser questionado sobre a transparência dos seus traços autobiográficos, que "todos os livros são autobiográficos, sobretudo Robinson Crusoé...Porque não se inventa nada, a imaginação é a maneira como se arruma a memória. Tudo tem a ver com a memória” (BLANCO, 2002, p.114).

A presença da infância é muito recorrente e serve como estratégia narrativa no primeiro Livro de Crónicas. Nesse livro, muitas crônicas tratam de pequenos acontecimentos familiares restituindo esses momentos de um tom nostálgico em que os tempos se sobrepõem. Em “Elogio do subúrbio", Lobo Antunes relembra a sua infância no subúrbio de Lisboa, em 
Benfica, entre "quintinhas, travessas, casas baixas, a ouvir as mães chamarem ao crepúsculo" (ANTUNES, 1999, p.13). Nesse tempo, em que Benfica representava o mundo, "e eu escrevia versos nos intervalos do hóquei, fumava às escondidas, uma das minhas extremidades tocava Jesus Correia e a outra Camões, era indecentemente feliz" (ANTUNES, 1999, p.14). Recuperar essa infância, momento de uma felicidade inocente, já não é mais possível, já que, segundo o narrador, se "hoje vou a Benfica não encontro Benfica. Os pavões calaram-se, nenhuma cegonha na palmeira dos Correios" (ANTUNES, 1999, p.14). Presentificar os momentos do passado só será possível através da memória.

não há pavões nem cegonhas e contudo a acácia dos meus pais, teimosa, resiste. [...] Resiste. E sei que junto do seu tronco, se fechar os olhos e encostar a orelha ao seu tronco, hei-de ouvir a voz da minha mãe a chamar

- Antóóóóóóóóónio (ANTUNES, 1999, p.15).

Tal passagem evoca com saudade os momentos do passado, momentos que estabelecem uma ligação muito estreita com a infância de Lobo Antunes. O mesmo acontece na crônica "A velhice", em que passado-presente-futuro se entrelaçam e o narrador busca apoio no passado para enfrentar a velhice que se aproxima.

Devo estar a ficar velho [...]. Comecei a gostar de sopa de nabiças. A apetecer-me voltar mais cedo para casa. A observar no espelho matinal desabamentos, rugas imprevistas, a boca entre parêntesis cada vez mais fundos. A ver os meus retratos de criança como se olhasse um estranho. A deixar de me preocupar com o futebol (ANTUNES, 1999, p.39).

Mesmo sentido o peso da idade, confessa que ainda gostaria

de ter um canivete de madrepérola com sete lâminas, saca-rolhas, tesoura, abre-latas e chave de parafusos. Ainda queria que meu pai me comprasse na feira de Nelas um espelhinho redondo com a fotografia de Yvonne de Carlo em fato de banho do outro lado. Ainda tenho vontade de escrever o meu nome depois de embaciar o vidro com o hálito. [...] Ainda me apetecia que meu avô me viesse fazer uma festa à cama (ANTUNES, 1999, p.40).

Em outras crônicas, o tom saudosista desaparece e o narrador recupera os pequenos momentos da infância sem nenhuma divagação profunda em relação à memória ou ao passado. Por exemplo, Em "Ontem, às três da tarde", o narrador recupera alguns momentos vividos com um amigo de infância chamado Pedro: "andávamos juntos na escola do senhor André, coleccionávamos a meias bonecos de bola e fotografias de artistas de cinema das pastilhas elásticas [...]" (ANTUNES, 1999, p.23). O mesmo acontece em "O Paraíso", em que o narrador conta que quando era pequeno havia em Benfica duas pastelarias - uma frequentada pelo proletariado e a outra "por senhoras de devoção inoxidável” (ANTUNES, 
1999, p.31). Em “O nadador olímpico e o amendoim”, a adolescência é retomada a partir da lembrança de "duas figuras tutelares" (1999, p.31) que marcaram o seu passado: o nadador olímpico e o pianista da Boîte. Já em "Crônica escrita em voz alta como quem passeia ao acaso", surgem as lembranças do hospital Miguel Bombarda quando o menino António ia com o pai.

Em "Crônica de Natal”, o narrador refere-se ao avô António Lobo Antunes, figura a quem Lobo Antunes dedica o Livro de Crônicas e que confessa ter tantas saudades. Nessa crônica, o narrador lembra com carinho especial os natais na casa do avô: "porque enquanto o meu avô viveu foi a época mais feliz da minha vida" (ANTUNES, 1999, p.195). Esse período permanece para o narrador como a lembrança de um tempo mítico e a esperança de que um dia possa sentir "de novo a sua força e ternura, sinta de novo, como sempre senti, que estando junto dele nunca nenhuma coisa má, nenhuma coisa triste, nenhuma coisa reles me poderia acontecer porque o meu avô não havia de deixar" (ANTUNES, 1999, p.197).

Em muitas crônicas é possível encontrar passagens de romances e até esboços para futuras narrativas. Personagens, temática e forma transitam de um espaço para o outro. Pedro Manuel Mateus afirma que

\begin{abstract}
na cronística de António Lobo Antunes, podem claramente ser detectados alguns dos grandes epicentros fundadores (no qual se inclui o tema da infância) da escrita deste autor, tratados, depois, de forma evidentemente mais exaustiva, em cada um dos romances publicados. E de reparar que muitos dos personagens, das obsessões pessoais e dos acontecimentos relatados nas crônicas são presença constante nos vários romances [...] (MATEUS, 2004, p.153).
\end{abstract}

Também Carlos Reis considera que nas crônicas "escutamos ecos muito nítidos da ficção já publicada e (provavelmente) premonições da ficção a vir” (REIS, 2011, p.204). Duas crônicas merecem atenção especial, pois nelas encontram-se pequenos esboços do romance Sôbolos rios que vão. Em "Carta ao meu tio João Maria", o narrador traz à tona a sua imagem de Nelas que vem carregada por um comboio a avançar "ao sol entre as folhas da vinha como um dedo que procura debaixo de uma saia”, a lembrança da " mãe muito nova e a voz dela por dentro do meu corpo", mas, sobretudo é a lembrança de "um caixão de criança trazido das tripas molhadas da taberna pelos ombros dos bêbedos, é a lua de agosto a amparar-me o medo com um gesso dos dedos, o que lembro de Nelas são os retratos dos mortos a que os sinos de domingo aumentavam o sorriso" (ANTUNES, 1999, p.92).

Sôbolos rios que vão principia com o personagem a recordar um enterro quando ainda era criança 
Assim que o médico lhe chamou cancro os sinos da igreja começaram o dobre e um cortejo alongou-se na direção do cemitério com a urna aberta e uma criança dentro, outras crianças vestidas de serafim de guerra ao caixão, gente de que notava apenas o ruído das botas e portanto não gente, solas e solas (ANTUNES, 2010, p.11).

Já a crônica "O coração do coração" é um pequeno resumo do que vem a ser Sôbolos rios que vão. Nessa crônica, Lobo Antunes manifesta como seria o livro que gostaria de escrever. Nesse livro,

tal como no último estádio de sabedoria dos chineses, todas as páginas fossem espelhos e o leitor visse, não apenas ele próprio e o presente em que mora mas também o futuro e o passado, sonhos, catástrofes, desejos, recordações. Uma história em que eu folheando-a no intuito de a corrigir, armado de um lápis vermelho destinado a uma carnificina de emendas, encontrasse de súbito, a acenar-me alegremente sentado num parágrafo como no muro da quinta do meu avô, o filho do caseiro que me ensinava a armar os pássaros e a roubar figos no pomar vizinho [...]. E não só o filho do caseiro: também a música de piano da Vila Ventura onde morava um par de solteironas feias que Chopin transfigurava, adoçando-lhes os olhos até à ternura insuportável e belíssima dos animais doentes que conversam conosco numa linguagem que com o tempo nos tornamos surdos (ANTUNES, 1999, p.45).

Nesse romance "de páginas de espelhos", "tropeçaria, à esquina de um capítulo, com os anos de Nelas, courts de ténis, a Serra da Estrela semeada de luzes, o ramo do castanheiro a assustar-me contra o postigo da insônia, a D. Irene a tocar harpa com as rolas amestradas dos dedos" (ANTUNES, 1999, p.45). E como "as páginas são espelhos lá estaria o meu rosto de agora e todos os rostos que tive" (ANTUNES, 1999, p.46), lá também "estariam os meus anos de menino do coro, a coreografia hipnótica da missa" (ANTUNES, 1999, p.46) e "se me aproximasse mais do livro toparia atrás dos meus avós [...], da minha mãe de mão em concha da orelha" (ANTUNES, 1999, p.47).

Sôbolos rios que vão seria o desejado "romance de páginas de espelhos", já nele o narrador Antoninho ou Senhor Antunes, deitado em uma cama de hospital, vítima de dores causadas pelo cancro no intestino, recupera os eventos do passado: a infância, o avô surdo, o pai com a criada na despensa "olha o teu filho a ver-nos", o pai jogando tênis "no hotel dos ingleses e a mãe a fazer-lhe a risca do cabelo" (ANTUNES, 2010, p.23). O livro está organizado em uma espécie de diário entre os dias 21 de março a 4 de abril de 2007. António Lobo Antunes na mesma época enfrentou um cancro no intestino. Para jogar com esse aparente autobiografismo, o autor opta por narrador heterodiegético. A voz desse narrador também se confunde com outras vozes como a voz do avô já falecido e a voz do enfermeiro.

Como já foi mencionado anteriormente, a narrativa principia com a imagem do personagem a olhar pela janela do hospital Santa Maria em Lisboa, entretanto ele não vê "as pessoas que entravam nem os automóveis entre as árvores nem uma ambulância" 
(ANTUNES, 2010, p.11), ele é transportado para o espaço da infância recuperado pela recordação de um enterro que outrora assistiu. $\mathrm{O}$ adulto se encontra com o menino, o hospital é contaminado pelos momentos vividos em Nelas e na nascente do Mondego, passado e presente se confundem criando um outro tempo, um outro espaço.

Antes de enfrentar a morte é preciso dar conta dos acontecimentos da infância, em uma espécie de dívida com o seu passado, a personagem recorda os momentos de aparente tranquilidade "quase tudo tranquilo na infância excepto a bomba a puxar limos do poço, o restolhar do milho e o louco de cobertor pelos ombros anunciando às cabras" (ANTUNES, 2010, p.14). A relação com a mãe: "E por segundos uma doçura de perfume e um sabor de carne viva, a palavra filho a fazer sentido, sou seu filho e ao dizer mãe digo uma coisa verdadeira como a palavra chávena ou a palavra tecto, não a palavra morte" (ANTUNES, 2010, p.18). E a ausência do pai “- Aquele não é o meu pai já não podiam ser amigos nem conseguia olhar-se quando ele ganhava ao tênis" (ANTUNES, 2010, p.76), mas, que afinal e por estar enfrentando a morte, a personagem gostaria de ter tido a oportunidade, "se o pai continuasse vivo, gostaria de propor-lhe - Toque-me" (ANTUNES, 2010, p.117).

É preciso rever/reviver os acontecimentos da infância porque só deste modo conseguirá articular o presente. Entretanto, os diálogos com o passado não acontecem de forma linear e com nitidez. Fazer as pazes com esse momento e consigo mesmo exige um certo esforço "não se lembrar do nome da governanta do senhor vigário preocupo-o, lembrava-se do avental, dos chinelos, do riso, não se lembrava do nome e por não se lembrar do nome não iria curar-se" (ANTUNES, 2010, p.12).

Gaston Bachelard, em A poética do Espaço, ao "tomar a casa como um instrumento de análise para a alma humana" (BACHELARD, 2008, p.19) mostra-nos como esse espaço feliz pode nos proteger, a casa "é o nosso canto do mundo. Ela é, como se diz freqüentemente, nosso primeiro universo. É um verdadeiro cosmos. Um cosmos em toda a acepção do termo. Até a mais modesta habitação, vista intimamente, é bela [...]” (BACHELARD, 2008, p. 24). A casa "mantém o homem através das tempestades do céu e das tempestades da vida. Ela é o corpo e alma. É o primeiro mundo do ser humano" (BACHELARD, 2008, p.26). Mas, mais do que isso, ela "é um corpo de imagens que dão ao homem razões ou ilusões de estabilidade" (BACHELARD, 2008, p.26).

Em Sôbolos rios que vão, a casa adquire uma importância crucial na comunhão da personagem com o seu passado seja através dos passos da mãe pela casa, dos encontros do pai com a empregada e até nos "cheiros das compotas da despensa" (ANTUNES, 2010, p.13). A 
casa da infância é casa reimaginada/reinventada através de uma memória que a personagem "trouxe para o hospital" (ANTUNES, 2010, p.40), que pode não ser a memória do que de fato aconteceu no passado. Uma memória escolhida para enfrentar os momentos de agonia e medo da morte "fazia-lhe jeito um rato de chocolate para enfrentar o medo, não fiques com o rato na palma, come-o, lembrou-se da avó a acariciar-lhe a nuca" (ANTUNES, 2010, p.48). A memória de "um pai diferente daquele que conhecia" (ANTUNES, 2010, p.48). E é possível falar da memória que questiona o próprio passado "ao aperceber-me que apenas a vela continuava no quarto e talvez eu a olhá-la, quantas vezes me interroguei se tudo isto existiu e esta terra existe com as vinhas, os comboios e o silêncio que os mineiros interrompiam" (ANTUNES, 2010, p.29).

Tanto nas crônicas que foram analisadas quanto no romance, o narrador ou o cronista recorrem à recordação autobiográfica (a família, a casa, a infância, Benfica) em um aparente jogo entre a ficção e a autobiografia. Pensar nesse jogo é considerar as artimanhas da escrita, sobretudo, a partir do modo que o sujeito, um ser de linguagem, se insere no processo de escrita. Como nos diz Filomena Barradas

\footnotetext{
Aquela que me parece ser a estratégia irônica de base para a obra de Lobo Antunes relaciona-se com a adopção da primeira pessoa verbal como instância de enunciação. Esse EU, vimo-lo lá atrás, é o detentor do (in)screver nas páginasespelhos e, porque o seu desejo é fazer com que o seu leitor se reveja nessas páginas, não cessa de se metamorfosear em distintos EUS, para os quais e possível definir diferentes quadros sociais, culturais, afectivos ou actanciais. Este deslizamento de EU-em-EU (ou de EU-em-TU?) pode ser submetido ao principio do livro das páginas de espelhos (BARRADAS, 2004, p.138).
}

Longe de pensar na inscrição do autor e toda a sua subjetividade como um espelhamento do real, a escrita é um desdobramento de si. Mais que salvação, a escrita, como nos disse Jacques Derrida, em "Força e Significação", ela abre espaço para o surgimento do Outro, pois "é a saída como descida para fora de si em si do sentido: metáfora-para-outremem-vista-de-outrem-neste-mundo" (DERRIDA, 1971, p.52), metáfora em que o ser que escreve deve ocultar-se para que o Outro apareça. Em Lobo Antunes, as rememorações do passado devem ser entendidas como um jogo retórico de linguagem em que o eu ficcionalizado efetua-se e se afeta pela escrita, não sendo possível enxergá-lo separado da linguagem.

\section{Referências}

ANTUNES, António Lobo. Sôbolos Rio Que Vão. Lisboa: Dom Quixote, 2010. Livro de crônicas. Lisboa: Publicações Dom Quixote, 1999. 
BACHELARD, Gaston. A poética do espaço. Trad. Antonio de Pádua Danesi. 2 ed. São Paulo:Martins Fontes, 2008.

BARRADAS, Filomena. Da literatura alimentar ao romance de espelhos - uma leitura do Livro de crônicas de António Lobo Antunes. In: CABRAL, Eunice; JORGE, Carlos; ZURBACH, Christine (orgs). A escrita e o mundo em António Lobo Antunes - Actas do Colóquio Internacional da Universidade de Évora. Lisboa: Dom Quixote, 2004. p. 133-139.

BLANCO, María Luisa. Conversas com António Lobo Antunes. Lisboa: Publicações Dom Quixote, 2002.

BRAGA, Suzana Márcia Dumont. Vestígios do estranho no familiar: as crônicas de Lobo Antunes. 2007, 206f. Tese (Doutorado em Letras). Pontifícia Universidade Católica de Minas: Belo Horizonte, 2007.

DERRIDA, Jacques. Força e significação. In: . A escritura e a diferença. Tradução Maria Beatriz da Silva. São Paulo: Perspectiva, 1971. p.11-52.

LEJEUNE, Philippe. O pacto autobiográfico: De Rousseau à Internet. Belo Horizonte: Editora da UFMG, 2008.

MATEUS, Pedro Manuel. A infância na cronística de António Lobo Antunes. In: CABRAL, Eunice; JORGE, Carlos; ZURBACH, Christine (orgs). A escrita e o mundo em António Lobo Antunes - Actas do Colóquio Internacional da Universidade de Évora. Lisboa: Dom Quixote, 2004. p.153-169.

REIS, Carlos Reis. A arte de crônica. In: ARNAUT, Ana Paula (org.). António Lobo Antunes: A crítica na imprensa 1980-2010 Cada um voa como quer. Almedina: Coimbra, 2011. p.203207.

Ad usum fabulae: a ficção da personagem. In: Boletín Galego de Literatura, 34, $2^{\circ}$ sem., 2005, p. 131-146.

[Recebido em agosto de 2012 e aceito para publicação em dezembro de 2012]

\section{Autobiography and representation of self in the narrative and in chronic by António Lobo Antunes}

Abstract: The present article is centered in the analytical reading of some chronicles published in the First Book of Chronicles (1998) and the novel Sôbolos rios que vão (2010), by António Lobo Antunes. This thesis shows how time, the memory, childhood and their respective events, as apparently autobiographical aspects are linked to the texture of some chronic and some novel. In fact, we can read in fiction several fictional possibilities and biographical. Structural elements of the Portuguese writer António Lobo Antunes narratives are pieces of a puzzle manipulated by an author. In the First Book of Chronicles and the novel, António Lobo Antunes revisits the past, not from a romantic view but from a critical process of self-reflection. Therefore, we will try to find meaning in the intertextual marks, in the author's voice slips, in the contact between literary and autobiographical discourses. The analysis is based on literary theory, with support from studies of Philippe Lejeune. 
Keywords: António Lobo Antunes. Autobiography. Fiction. Chronic.

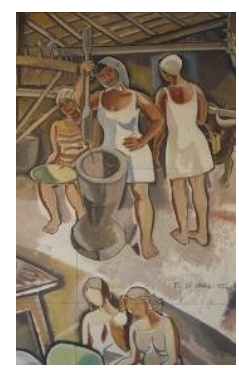

